\title{
Impact of Model Complexity on Mixed AC/DC Transient Stability Analysis
}

\section{Document Version}

Accepted author manuscript

Link to publication record in Manchester Research Explorer

\section{Citation for published version (APA):}

Fatah Mochamad, R., \& Preece, R. (2017). Impact of Model Complexity on Mixed AC/DC Transient Stability Analysis. In The 13th IET international conference on AC and DC Power Transmission

\section{Published in:}

The 13th IET international conference on AC and DC Power Transmission

\section{Citing this paper}

Please note that where the full-text provided on Manchester Research Explorer is the Author Accepted Manuscript or Proof version this may differ from the final Published version. If citing, it is advised that you check and use the publisher's definitive version.

\section{General rights}

Copyright and moral rights for the publications made accessible in the Research Explorer are retained by the authors and/or other copyright owners and it is a condition of accessing publications that users recognise and abide by the legal requirements associated with these rights.

\section{Takedown policy}

If you believe that this document breaches copyright please refer to the University of Manchester's Takedown Procedures [http://man.ac.uk/04Y6Bo] or contact uml.scholarlycommunications@manchester.ac.uk providing relevant details, so we can investigate your claim.

\section{OPEN ACCESS}




\title{
Impact of Model Complexity on Mixed AC/DC Transient Stability Analysis
}

\author{
Rian Fatah Mochamad*, Robin Preece* \\ *School of Electrical and Electronic Engineering, The University of Manchester, Manchester, United Kingdom \\ rian.fatahmochamad@manchester.ac.uk; robin.preece@manchester.ac.uk
}

Keywords: VSC-HVDC, MMC, mixed AC/DC, modelling, transient stability.

\begin{abstract}
Model complexity may have a significant impact on transient stability results of mixed AC/DC systems. The dynamics of various mixed AC/DC models with a focus on different generator orders and multi-level modular converter (MMC) VSCHVDC model types is investigated within this paper. MMC VSC-HVDC converter models are based on average value model (AVM) and simplified AVM, while $2^{\text {nd }}, 3^{\text {rd }}$ and $6^{\text {th }}$ order generator models are formulated within the research The paper also considers the impact of inner current control bandwidth. Based on the simulation result, substantial change over the transient stability result is seen with respect to different types of modelling complexity used within the research.
\end{abstract}

\section{Introduction}

The growing need to interconnect large renewable energy sources (RES) coupled with the deregulation of power systems and difficulties in securing the right of way make HVDC an increasingly attractive option for transmission system developments. Voltage source converter (VSC) HVDC permits controllability of active and reactive power, thus offering the possibility for ancillary service support of power systems [1]. Due to these abilities, there has been a rise in installed and planned VSC-HVDC capacity over the last decades which has increased the need for mixed AC/DC system studies incorporating appropriate VSC-HVDC models.

Following the emergence of VSC-HVDC, there has been significant development in the converter topologies - stating with two-level and developing to multi-level modular converters (MMC). Presently, MMC is widely acknowledged as the most attractive topology due to several advantages including low losses and low harmonic content [2]-[4]. Investigations regarding the dynamic response of various MMC VSC-HVDC models can be found in [3], [5] where the different outputs and characteristics to be expected with different models are highlighted.

When modelling MMC VSC-HVDC for power system stability analysis it is impractical and uncessary to model the entire converter including all switching elements and protctive circuits. Instead, simplied models are used. The average value model (AVM) and simplified AVM are types of MMC models which commonly used in power system stability due to their quick computational time and accepted accuracy [3]. AVM is a kind of MMC model developed to represent the average response of the VSC-converter and its component by using controlled source and switching of an averaged function with an addition on harmonics and converter losses. On the other hand, a perfectly sinusoidal signal and no harmonics are assumed within simplified AVM, which is generally considered to make it suitable for mediumterm and long-term power system simulation. Despite the fact that switching devices are not meticulously modeled, AVM and simplified AVM still yield accurate results due to the assumption that in power system stability, all valve-related processes such as firing angle and switching are very stable and have very quick responses.

Additionally, transient stability assessment of mixed AC/DC systems (particularly with significant penetration of HVDC) is of significant importance due to the possible system impacts. It is well known that model complexity has a significant impact on the results of stability analysis and this has been extensively studied for traditional AC power systems [6]. Likewise, HVDC converter model complexity is increasingly investigated and there has been some recent work to improve model standardization [3]. However, less well understood is the combined impact of both AC and HVDC models on stability analysis. Typical work in this area has focused on either the AC or DC components, but rarely both. Therefore, it is important to establish the necessary AC and DC system model complexity that is needed to yield an accurate stability analysis. The resultant necessary models can act as a standard for mixed AC/DC modeling studies suited for transient stability assessment.

The paper will compare and analyze the transient stability dynamics of various mixed AC/DC models with a focus on different generator and VSC-HVDC models. The generator model order investigated within the research will range from 2nd order (classical), 3rd order (neglecting stator flux linkage) and 6th order (considering leakage reactance) with PSS and AVR installed. VSC-HVDC converter models will be based on average value model (AVM) and simplified AVM (with both of them are identical with CIGRE type 5 and type 6 models [3]). An investigation over the impact of inner current bandwidth is also carried out within the research with normal, very fast and very slow bandwidths introduced. This investigation will highlight the impact that this control loop can have on the transient stability of a mixed AC/DC system. A modified version of the Kundur two-area network [7] with an infeed VSC-HVDC will be considered in this research as 


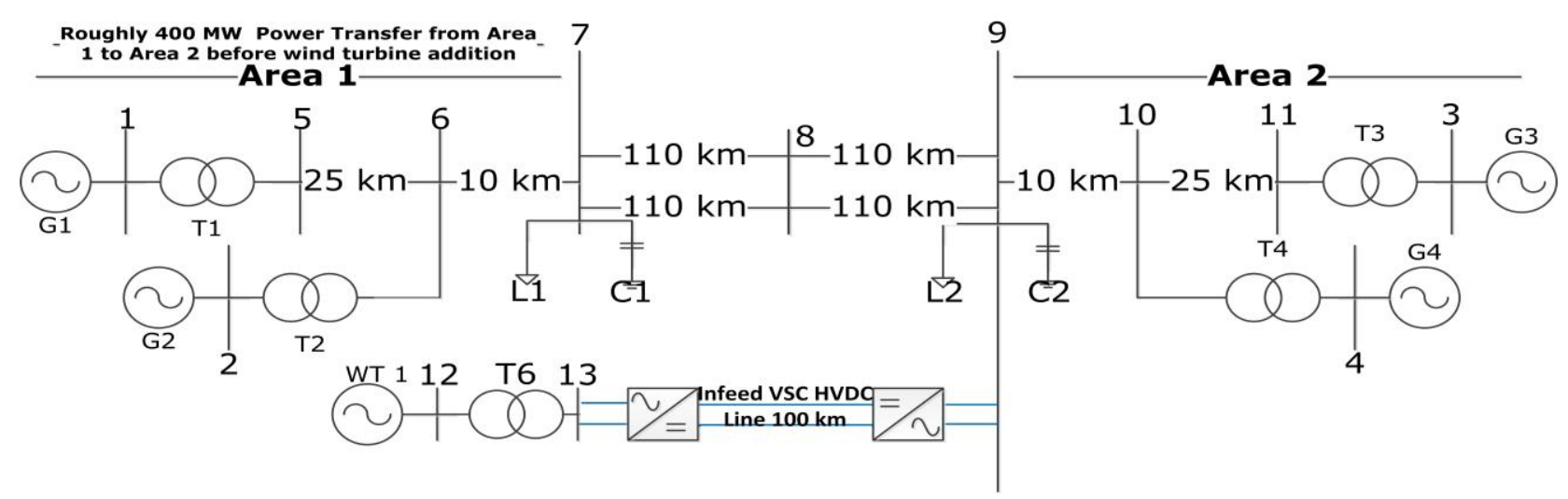

Figure 1: Modified two area network for transient stability analysis, adopted and modified from [7]

shown in Figure 1. All simulations are performed using DIgSILENT PowerFactory 2016 [8].

\section{Modelling of Mixed AC/DC System}

This section will outline the models used in order to aid understanding of the results and the later analysis. For further details on all models, the included references should be further explored.

\subsection{VSC HVDC}

Despite there existing various models of MMC VSC-HVDC, the basic concept can be explained using Figure 2.

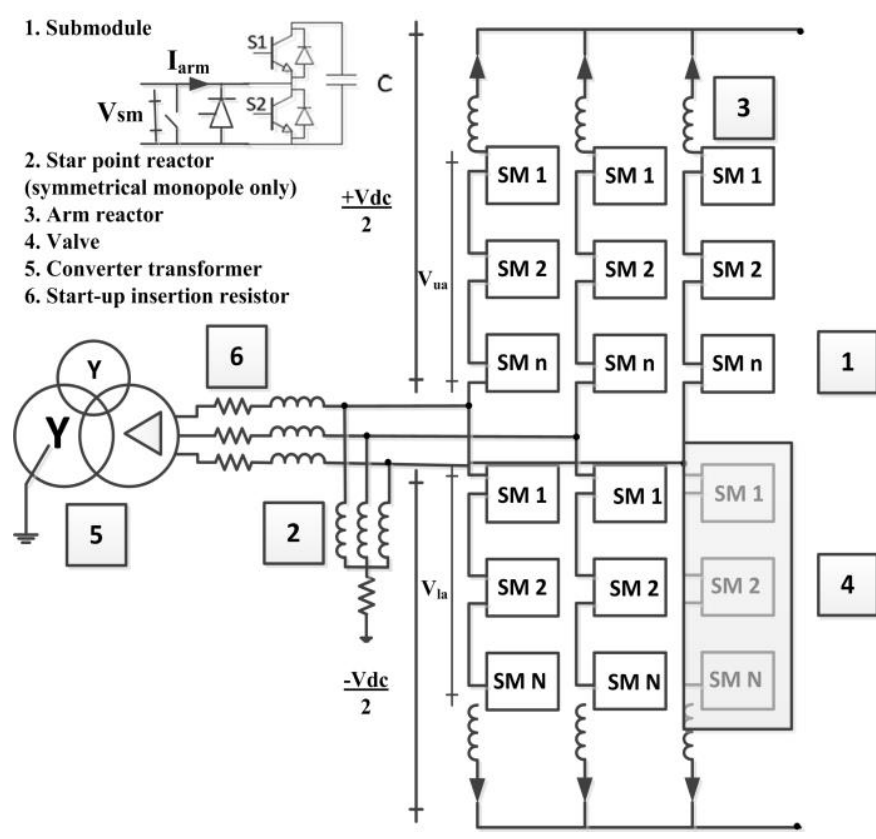

Figure 2: Representation of MMC

The structure of the MMC is shown in Figure 2. Concerning [2], the mathematical model of the MMC can be derived as follows. For the arm voltages:

$$
\begin{gathered}
V_{j}=\frac{V_{d c}}{2}-V_{u j}-L_{a r m} \frac{d I_{u j}}{d t}-I_{u j} R_{a r m} \\
V_{j}=V_{l j}-\frac{V_{d c}}{2}+L_{a r m} \frac{d I_{l j}}{d t}+I_{l j} R_{a r m}
\end{gathered}
$$

$$
j=a, b, c
$$

For the arm currents:

$$
\begin{gathered}
I_{u j}=\frac{I_{j}}{2}+\frac{I_{d c}}{3}+I_{j_{-} \text {circulate }} \\
I_{l j}=-\frac{I_{j}}{2}+\frac{I_{d c}}{3}+I_{j_{-} \text {circulate }}
\end{gathered}
$$

Where $I_{j}$ circulate denotes the circulating currents resulting from the unevenly generated DC voltages of the three converter legs. By substituting (3) - (4) into (1) - (2) and then summing the resultant yields:

$$
V_{j}=\frac{V_{l j}-V_{u j}}{2}-L_{a r m} \frac{d I_{u j}}{d t}-I_{j} \frac{R_{a r m}}{2}
$$

Equation (5) shows that the phase voltages of the MMC can be controlled by varying the voltages in the upper arm and the lower arm. This forms the foundation of MMC control methods. Thus, the converter arm voltages are controlled by the number SMs that are turned on with respect to the capacitor on each SM. The different types of MMC VSC-HVDC models vary based on how the switch and the capacitors are modelled.

\subsubsection{Average Value Model}

The Average Value Model (AVM) - also referred to as a type 5 model of CIGRE - aims to replicate the average response of the VSC and its components by using controlled sources and switching of averaged function [3]. The modelling of an AVM can be viewed from two sides: the AC side and the DC side. The AC side is represented by a controlled voltage for each arm which is similar to Figure 2. The AC side is modelled based on the assumption that capacitor voltage of each arm is equal, thus eliminating circulating current, $I_{j_{\text {circulate }}}$. Due to this modelling principle, the AC side of the AVM is suitable for electro-magnetic transient (EMT) simulation. The DC side is modelled based on the power balance between the $\mathrm{AC}$ and DC sides subject to the converter losses. Two current sources are introduced in the DC side for DC current and losses current modelling. An equivalent capacitance, $C_{e q}$ is also introduced with respect to the number $\mathrm{N}$ of submodule capacitors on the AC side. The detail of the DC side modelling can be seen in Figure 3. 


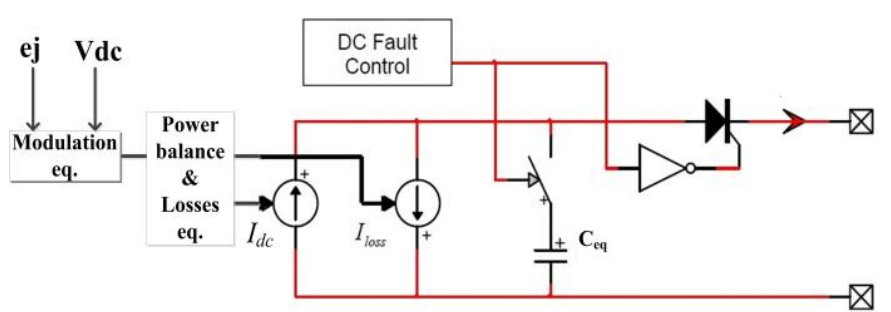

Figure 3: DC side representation of AVM

\subsubsection{Simplified Average Value Model}

The simplified AVM uses a large time scale approximation for electrical components with no harmonics and a perfectly sinusoidal output signal from the converter is assumed. This makes it suitable for medium-term and long-term power system simulation [3]. Consequently, the system is always balanced even during a fault conditions. The simplified model is based on a fundamental frequency approach in which the AC part of simplified AVM is modelled only as positive-sequence component while the DC side is represented with AC-DC power transfer with no-load losses. The detail of simplified AVM representation is shown in Figure 4.

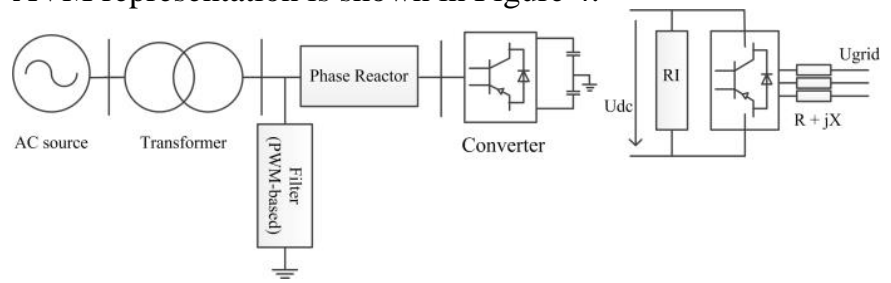

Figure 4: Simplified AVM representation.

\subsection{Generator Model}

The synchronous generator can be modelled with varying levels of complexity. DIgSILENT PowerFactory uses sixth order generator model as its default model and lower order model can be incorporated into the software. This work will consider sixth order, third order, and classical generator models. The sixth order generator model includes leakage reactance. The third order generator model is based on the elimination of damper winding dynamics, and the classical generator model uses a constant voltage behind a transient reactance. The modelling principles and mathematical derivation are more thoroughly covered in [9] and [10].

\section{Control and Transient Stability Assessment}

The upper-level control task is to transform dispatch command signals into voltage references for the IGBTs in lower level control by utilizing two types of control loop: inner and outer loops. The outer loop is designed to convert the reference setting into a current reference while the inner loop transforms the current reference into a voltage reference to be processed by IGBTs [3].

\subsection{Outer Loop Control}

Based on the assumption that $\mathrm{d}-\mathrm{q}$ control approach is used, there are two degrees of freedom for the outer loop of off- shore connection. The simulation presented within this paper employs $V_{a c}-f$ control in outer loop of rectifier side and utilizes $V_{d c}-Q$ control on its inverter side.

$V_{a c}-f$ control is best utilized where VSC is the dominant voltage source as it acts as reference bus for offshore connection [15]. $V_{a c}$ control is realized by utilizing the modulation principle between the AC voltage and DC voltage as shown in (6). Frequency control is applied by setting the reference frequency directly. The complete block diagram of $V_{a c}-f$ control is shown in Figure 5.

$$
P_{m_{-} i n}=m_{a}=1.633 \frac{V_{a c_{-} p u} * V_{a c_{-} \text {base }}}{V_{d c_{-} p u} * V_{d c_{-} \text {base }}}
$$

DC-link voltage outer loop is developed based on the power flow from the equivalent capacitance, $C_{e q}$ in the DC side of the converter with the final equation is shown in (7). Details of equation derivation can be found in [2].

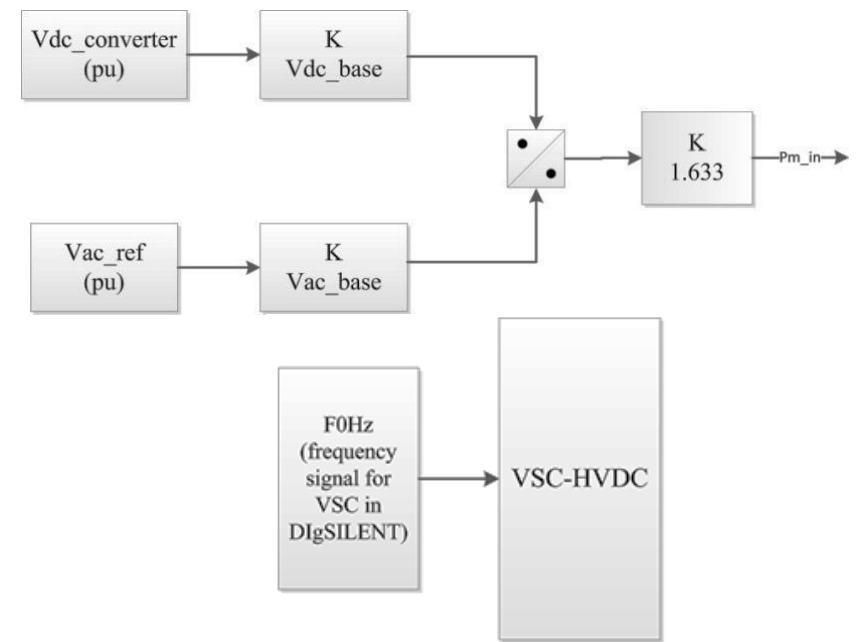

Figure 5: $V_{a c}-f$ control implementation.

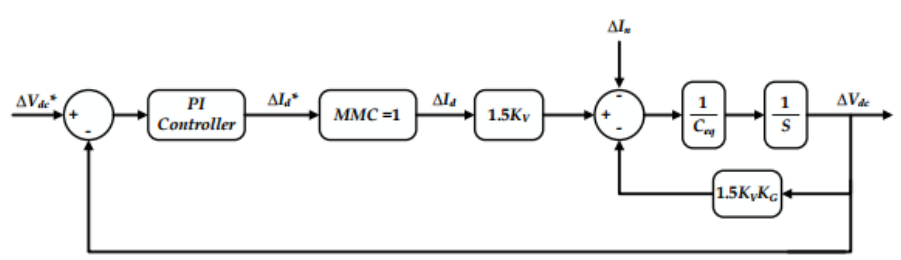

Figure 6: Dc-link voltage control

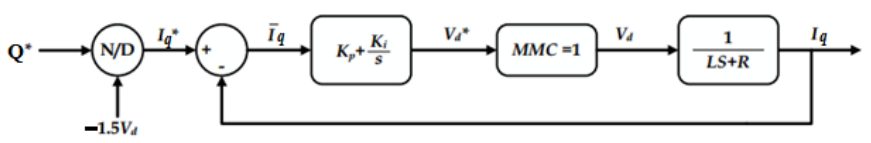

Figure 7: Reactive power control

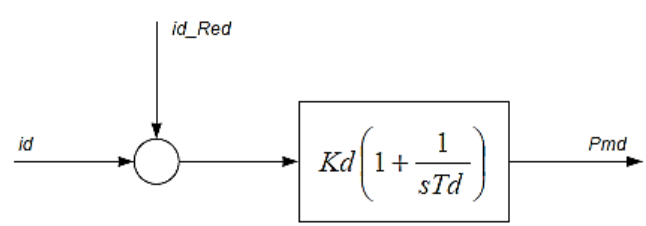

Figure 8: Built in inner loop control Power Factory 


$$
\frac{d \Delta V_{d c}}{d t}=\frac{1}{C_{e q}} \Delta I_{n}-\frac{3 V_{n d 0} I_{d 0}}{2 C_{e q} V_{d c 0}^{2}}+\frac{3 V_{n d 0}}{2 C_{e q} V_{d c}} \Delta I_{d}
$$

The reactive power control is based on power decoupling in the q-axis at the point of common coupling (PCC) with equation derived from [2] and shown in (8).

$$
Q_{d q}=-\frac{3}{2} V_{x d} i_{q}
$$

If PI control is used and the converter is assumed as ideal (transfer function $=1$ ), the state block diagram for $V_{d c}-Q$ outer loop are shown in Figure 6 and Figure 7. Note that $\frac{1}{L S+R}$ represents the transfer function of one converter arm in the MMC converter.

\subsection{Inner Loop Control}

This paper utilizes the inbuilt inner loop control as shown in Figure 8. Pmd is phase modulation index for the d-axis which translates into $V_{d}$ which is then fed into lower level control. A similar mechanism exists for Pmq and the q-axis.

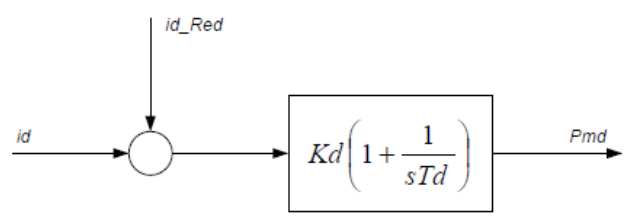

Figure 8: Built in inner loop control Power Factory

This research considers variation of inner loop control bandwidth by introducing three types of bandwidth: normal, very fast and very slow. The inner loop control must be coordinated with the outer loop control in order to achieve the desired operation. Control parameters are tuned using a second-order plant approximation. A normal bandwidth is defined as damping ratio of $\zeta=1.0$ with inner loop and outer loop bandwidths are targeted as $20 \mathrm{~Hz}$ and $4 \mathrm{~Hz}$ respectively. While inner loop control with very fast and very slow bandwidth are defined as $200 \mathrm{~Hz}$ and $8 \mathrm{~Hz}$ respectively with a constant value of $4 \mathrm{~Hz}$ maintained in the outer loop. Final controller gains $K p$ and $K i$ of the resulting $V_{d c}-Q$ control are shown in Table 1 .

\begin{tabular}{c|cccc}
\hline \multirow{2}{*}{$\begin{array}{c}\text { Control } \\
\text { Mode }\end{array}$} & \multicolumn{2}{|c}{ Inner Loop } & \multicolumn{2}{c}{ Outer Loop } \\
\cline { 2 - 5 } & $K p$ & $K i$ & $K p$ & $K i$ \\
\hline Normal & 2.252 & 26 & 5 & 17.4 \\
Very Fast & 22.52 & 2600 & 5 & 17.4 \\
\hline Very Slow & 0.45 & 1.043 & 5 & 17.4 \\
\hline
\end{tabular}

Table 1: Controller gains for $V_{d c}-Q$ control

Please note that since $V_{a c}-f$ does not use inner loop control as its control is connected directly to converter.

\subsection{Transient Stability Index (TSI)}

The transient stability index (TSI) used within this research is TSI based on power-angle equation as shown in (9) [11].

$$
\mathrm{TSI}=\frac{360-\delta_{\max }}{360+\delta_{\max }} \times 100
$$

Equation (20) denotes the TSI in which $\delta_{\max }$ is the maximum rotor angle separation of any two generators at the same time in the post-fault response. The system is stable if TSI $\geq 0$. This index will be used to help quantify variations seen in the results obtained.

\section{Result and Discussion}

\subsection{Impact of Generator Order Model}

The first simulation aims to investigate the impact of generator order complexity towards rotor angle and mixed AC/DC power flow. Simplified AVM and normal bandwidth are selected as VSC model and inner loop control. A three phase $100 \mathrm{~ms}$ self-clearing fault is applied to the system at bus 8 at a time of $3 \mathrm{~s}$. In order to better showcase post-disturbance response, the graphs are plotted from $2.5 \mathrm{~s}(0.5 \mathrm{~s}$ before disturbance) and a zoomed part of the graph will be provided for every part which need further clarity.

Since in every simulation, generator G4 consistently has the largest rotor angle displacement with respect to reference generator, only the G4 rotor angle is depicted in Figure 9 (a). Figure 9 (b) shows the power generated from G4, while Figure 9 (c) displays the VSC-HVDC power infeed. As shown in Figure 9 (a), the largest rotor angle displacement is experienced by classical generator model with both of 3rd order and $6^{\text {th }}$ order generator model sharing similar first swing behaviour. The difference is $3^{\text {rd }}$ order generator model indicating continuous damping characteristic which $6^{\text {th }}$ order generator did not possess. The largest displacement which is experienced by the classical model is due to the lack of transient and sub-transient components. The nature of the classical model which does not have internal EMF variation also negates the function of both AVR and PSS, resulting in an uncontrolled oscillatory response. Meanwhile, the similar behaviour which is possessed by $3^{\text {rd }}$ and $6^{\text {th }}$ order generator models is caused by the similarity in transient and sub-transient modelling. Despite the $6^{\text {th }}$ order generator model including the leakage reactance, as reported in [12] the negative damping impact of leakage reactance to the transient stability is minimized due to the presence of AVR and PSS. As a result, the $6^{\text {th }}$ order and $3^{\text {rd }}$ order generator models share similar oscillatory behaviour.

The findings regarding the impact of generator order model on rotor angle displacement are supported by the power flow plots shown in Figure 9 (b) and 9 (c). Power generated from G4 with the classical model oscillates after being subjected to the disturbance and experiences difficulties in regaining its steady state condition. On the other hand, both the $3^{\text {rd }}$ order and $6^{\text {th }}$ order model display reduced power swings and are quicker to reach steady state conditions. The difference is that the power from G4 using a $6^{\text {th }}$ order model encounters a higher swing than the $3^{\text {rd }}$ order model. Again this relates positively with the finding regarding the rotor angle displacement in Figure 9 (a). The HVDC infeed, as shown in Figure 9 (c) also shows similar characteristics to the G4 


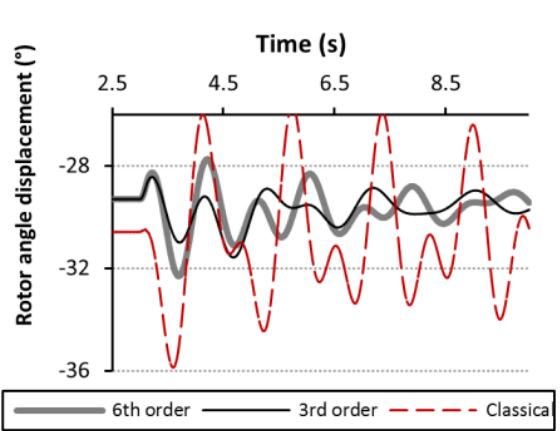

(a)

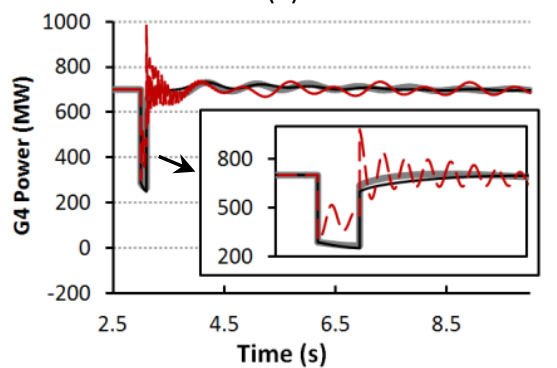

(b)

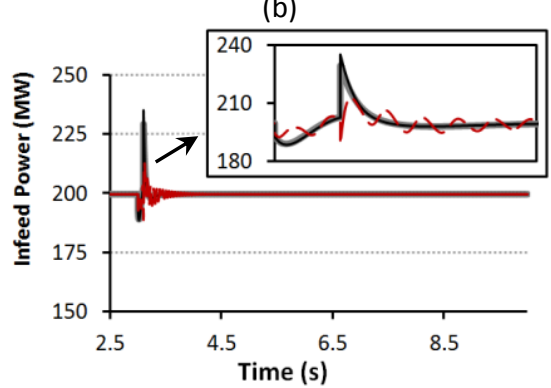

(c)

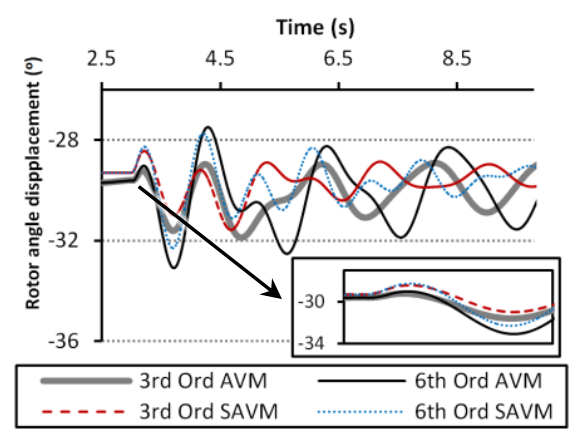

(d)

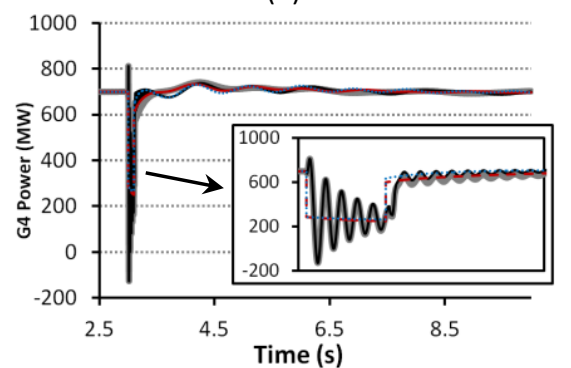

(e)

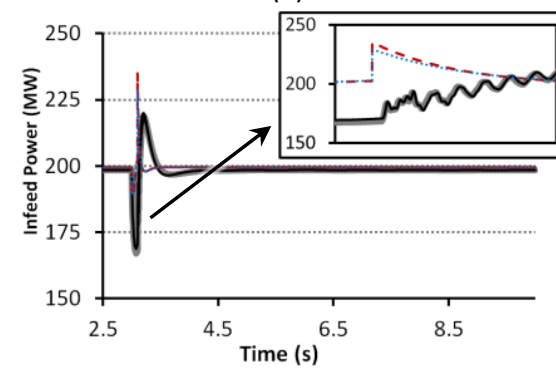

(f)

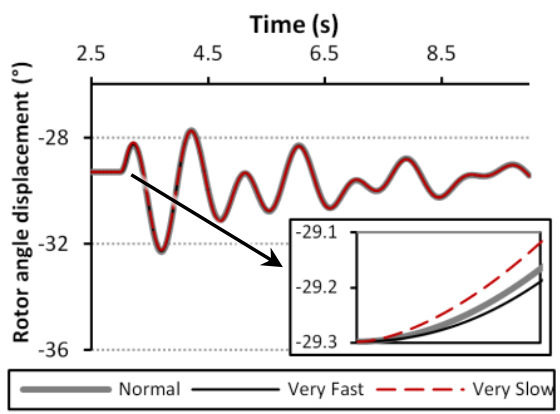

(g)

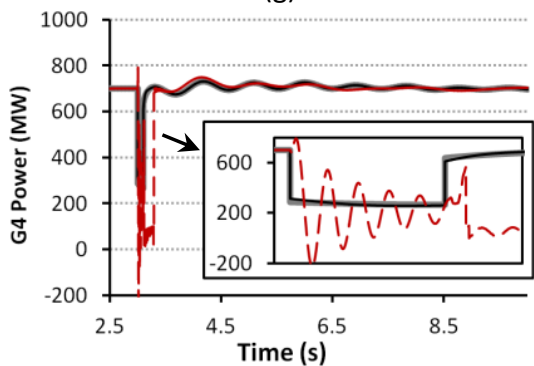

(h)

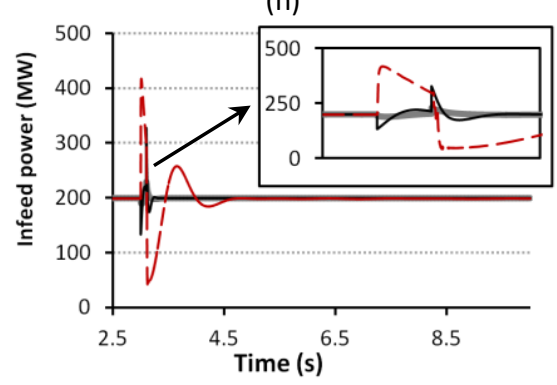

(i)

Figure 9 (a) - (c) Impact of generator order in rotor angle displacement and power flow in generator 4 and offshore Figure 9 (d) - (f) Impact of VSC HVDC model in rotor angle displacement and power flow in generator 4 and offshore Figure $9(\mathrm{~g})$ - (i) Impact of bandwidth variation in rotor angle displacement and power flow in generator 4 and offshore

response with the classical model suffering from oscillatory power, while both the $3^{\text {rd }}$ and $6^{\text {th }}$ order models producing a more well damped response.

\subsection{Impact of VSC Model}

The impact of the VSC model is investigated in the second study. As shown in Figure 9 (d), (e) and (f); only $6^{\text {th }}$ and $3^{\text {rd }}$ generator order are selected as the classical model shows largest discrepancy in the previous simulation. Both $6^{\text {th }}$ and $3^{\text {rd }}$ order models are simulated with AVM and simplified AVM as its VSC-HVDC model. Based on the simulation results, it can be noted that AVM-based simulation has a marginally lower rotor angle displacement and slightly more damped characteristic compared with simplified AVMs. The main cause of the AVM behaviour is the internal dynamics which are caused by the presence of submodules as compared to the simplified AVM which is only modelled as a perfectly balanced sinusoidal source. The zoomed graph in Figure 9 (f) is also worth noting as it reveals the sawtooth-like power from the AVM during disturbances, a phenomenon resulting from the modulation of the converter which constantly tries to keep its voltage (and therefore is power) to its steady state value by controlling the state of each submodules. Consequently, the G4 power response is affected by the converter response and a closer look at Figure 9 (e) shows that power response with the AVM model is oscillating around for $100 \mathrm{~ms}$ compared to the smoother response from simplified AVM.

\subsection{Impact of Inner Loop Bandwidth}

As discussed in Section 3.2, normal, very fast and very slow bandwidths are introduced to investigate the impact of inner loop bandwidth variation on the transient stability of the system. In order to provide more depth, the simulation will be carried out using a $6^{\text {th }}$ order generator model. Simplified AVM is selected as its perfectly balanced sinusoidal waveform makes it easier to investigate the impact of bandwidth variation. The results are shown in Figure $9(\mathrm{~g}),(\mathrm{h})$ and (i).

Despite only causing a slight difference in the overall rotor angle displacement as shown in Figure $9(\mathrm{~g})$, a significant temporary difference can be seen in the power flowing from G4 and the HVDC infeed. The best response with respect to the HVDC infeed is achieved with normal bandwidth utilization as its power spike in the first swing after disturbance is recorded at $229.2 \mathrm{MW}$ (a 14.6\% overshoot), while both of very fast and very slow bandwidth are listed at $327.5 \mathrm{MW}$ and 417.4 MW (equivalent to $63.7 \%$ and $108 \%$ of overshoot) 


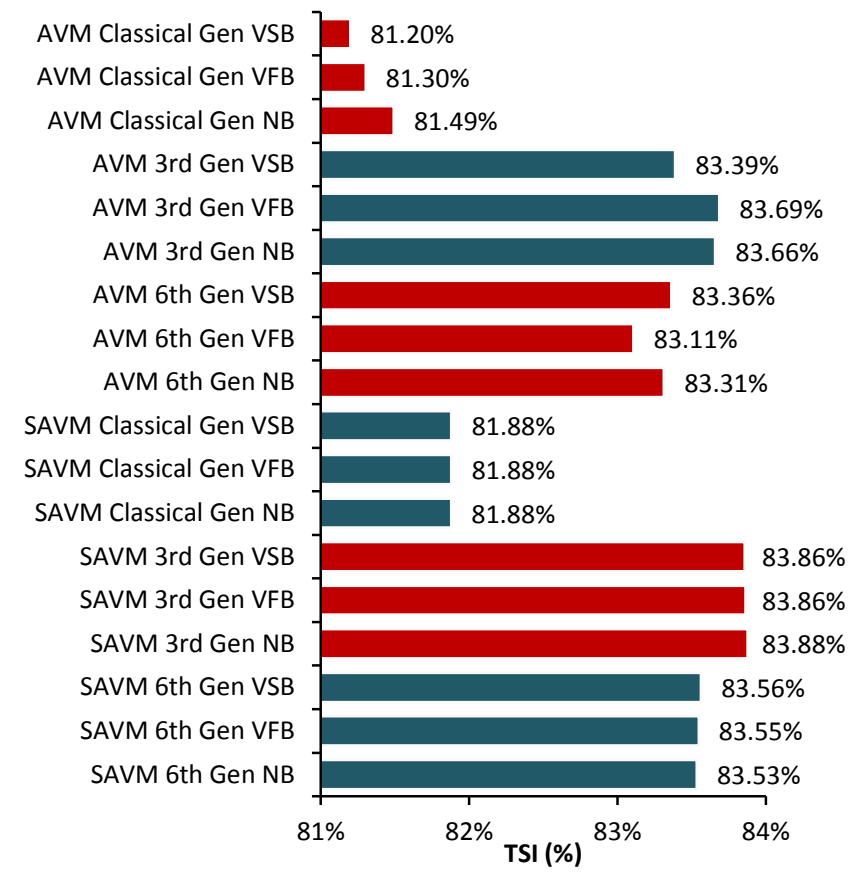

NB: Normal Bandwidth VFB: Very Fast Bandwidth VSB:Very Slow Bandwidth

Figure 11: TSI for different models types and bandwidths

respectively. The low overshoot in the HVDC infeed from normal bandwidth is compensated by the response of G4 which reaches $636 \mathrm{MW}$ at the same time (compared to 610 MW and 260 MW responses of very fast bandwidth and very slow bandwidth). Despite the fact that the use of a very fast bandwidth results in higher overshoot, its settling time is slightly slower than normal bandwidth. It is also worth noting that the usage of a very slow bandwidth degrades the performance of the system as both power from G4 and the HVDC infeed recover more slowly. Therefore, it can be concluded that offshore generation control in this simulation is best utilized using normal bandwidth which correlates positively with result reported in [13].

\subsection{Transient Stability Index of Different type of Models}

This section summarizes the TSI of different types of model tested within this research. As shown in Figure 11, a total of 18 model combinations are investigated in this paper. The result shows relatively small changes over TSI with respect to variation of generator order model, converter model and bandwidth of inner loop control. Despite small changes, it is worth noting that given a larger share of offshore converter interfaced generation in the future; the transient stability of the system may become more greatly affected. Other transient stability metrics should be explored as significant changes in the power flowing through the system in the previous simulations only yield relatively small changes in the TSI.

\section{Conclusion}

In general, the use of AVM models in the simulations results in a longer time to reach steady state conditions than simpli- fied AVMs due to presence of the submodules and the associated modulation schemes. It was seen that $6^{\text {th }}$ order and $3^{\text {rd }}$ order of generator models result in similar first swing characteristics during mixed AC/DC transient stability analysis with $6^{\text {th }}$ order models showing greater damping characteristics. The variation of VSC-HVDC inner current loop control bandwidth shows the deleterious impact of improper bandwidth selection. In terms of resulting TSI values, the difference between the models is relatively small however not completely negligible. Based on these findings, there is a need to further investigate the impact of modelling complexity in a more complex and converter-rich mixed AC/DC systems using different metrics of system performance and stability.

\section{References}

[1] D. Jovcic and K. Ahmed, High Voltage Direct Current Transmission - Converters, Systems and DC Grids, 1st ed. Wiley, 2015.

[2] S. Gao and M. Barnes, "An Introduction to VSC-HVDC," Manchester, 2015.

[3] Cigré Working Group B4.57, Guide for the Development of Models for HVDC Converters in a HVDC Grid, vol. 604, no. December. 2014.

[4] B. R. Andersen, "Topologies for VSC transmission," in Seventh International Conference on $A C$ and $D C$ Transmission, 2001, vol. 2001, pp. 298-304.

[5] A. Beddard, M. Barnes, and R. Preece, "Comparison of Detailed Modeling Techniques for MMC Employed on VSCHVDC Schemes," IEEE Trans. Power Deliv., vol. 30, no. 2, pp. 579-589, Apr. 2015.

[6] N.-T. Trinh, M. Zeller, K. Wuerflinger, and I. Erlich, "Generic Model of MMC-VSC-HVDC for Interaction Study With AC Power System," IEEE Trans. Power Syst., vol. 31, no. 1, pp. 27-34, Jan. 2016.

[7] P. Kundur, N. J. Balu, and M. G. Lauby, Power system stability and control, vol. 7. McGraw-hill New York, 1994.

[8] DIgSILENT GmbH, "User Manual PowerFactory 2016," 2016.

[9] R. Preece, "Improving the Stability of Meshed Power Networks: A Probabilistic Approach Using Embedded HVDC Lines," p. 209, 2013.

[10] J. T. G. Weckesser, H. Jóhannsson, and J. Østergaard, "Impact of model detail of synchronous machines on real-time transient stability assessment," 2013 IREP Symp. Bulk Power Syst. Dyn. Control - IX Optim. Secur. Control Emerg. Power Grid, pp. 19, 2013.

[11] L. Shi, S. Dai, Y. Ni, S. Member, L. Yao, and M. Bazargan, "Transient Stability of Power Systems with High Penetration of DFIG Based Wind Farms," Power Energy Soc. Gen. Meet. 2009. PES '09. IEEE, pp. 1-6, 2009.

[12] S. Nagano, D. Hiramatsu, K. Hirayama, Y. Uemura, M. Kakiuchi, K. Koyanagi, T. Satoh, and K. Nagasaka, "Effects of Field Mutual Leakage Reactance in Rotor Circuit of Synchronous Generator on the Transient and Dynamic Behavior," in Power Engineering Society General Meeting, IEEE, 2005, pp. 1-7.

[13] M. Amin, A. Rygg, and M. Molinas, "Active Power Flow Direction Effect on Stability in Multi-terminal VSC-HVDC Transmission System in Integrating Wind Farm," in IEEE 17th Workshop on Control and Modeling for Power Electronics (COMPEL), 2016, pp. 1-8. 